\title{
Comissão Rondon, doenças e política: "Região do Madeira: Santo Antônio", de Joaquim Augusto Tanajura - uma outra visão do Alto Madeira em 1911
}

\author{
The Rondon Commission, diseases, and politics: "Região do \\ Madeira: Santo Antônio," by Joaquim Augusto Tanajura - another \\ view of the Alto Madeira in 1911
}

André Vasques Vital

Mestrando do Programa de Pós-graduação em História das Ciências e da Saúde/Casa de Oswaldo Cruz/Fundação Oswaldo Cruz; bolsista Capes sob orientação do doutor Gilberto Hochman. Rua Pedro Álvares Cabral, 1136 26520-534 - Nilópolis - RJ - Brasil vasques_hist@yahoo.com.br
VITAL, André Vasques. Comissão Rondon, doenças e política: "Região do Madeira: Santo Antônio", de Joaquim Augusto Tanajura - uma outra visão do Alto Madeira em 1911. História, Ciências, Saúde - Manguinhos, Rio de Janeiro, v.18, n.2,abr.-jun. 2011, p.545-557.

Resumo

Comenta o artigo "Região do Madeira: Santo Antônio", do médico Joaquim Augusto Tanajura (1878-1941), chefe do serviço de saúde da Comissão Rondon de 1909 a 1912. Publicado em 5 de junho de 1911, no Jornal do Commercio de Manáos, o artigo insere-se no contexto inicial de redescoberta dos sertões, quando emergiram denúncias sobre o cenário de abandono e doenças no interior do Brasil, e dialoga com as primeiras viagens científicas promovidas pelo Instituto Oswaldo Cruz. Ele permite analisar a atuação de membros da Comissão Rondon na dinâmica política local e as controvérsias ligadas à construção da imagem de sertão e seus habitantes, no período.

Palavras-chave: Alto Madeira; Santo Antônio do Madeira; malária; Comissão Rondon; Brasil.

\section{Abstract}

Physician Joaquim Augusto Tanajura (1878-1941), head of health services for the Rondon Commission from 1909 to 1912, wrote a paper about the first scientific journeys sponsored by the Oswaldo Cruz Institute. Entitled "Região do Madeira: Santo Antônio," it was published in the newspaper Jornal do Commercio de Manáos on June 5, 1911, at a time when rediscovery of Brazil's sertões had just begun and indictments were starting to be lodged about the state of abandonment and disease in which the interior of the country lay. Through Doctor Tanajura's article, the present text analyzes both the engagement of members of the Rondon Commission in local political dynamics and the era's controversies about construction of the image of the sertão and its inhabitants.

Keywords: Alto Madeira; Santo Antônio do Madeira; malaria; Rondon Commission; Brazil. 
$\mathrm{E}$ m 1907, o presidente do Brasil Affonso Penna (1906-1909) convidou o coronel Cândido Mariano da Silva Rondon para chefiar a comissão que teria por tarefa construir uma linha telegráfica ligando Mato Grosso ao vale do rio Madeira, no Amazonas. A Comissão Construtora de Linhas Telegráficas de Mato Grosso ao Amazonas teve como ponto inicial de sua atuação a cidade de Cuiabá, ao sul, e como ponto final o povoado de Santo Antônio do Madeira, ao norte (atual cidade de Porto Velho).

O objetivo mais imediato era ligar o Rio de Janeiro aos territórios do Amazonas, Acre, Alto Purus e Alto Juruá, através da capital de Mato Grosso, com o fim de melhorar a comunicação e contribuir para a vigilância das fronteiras nacionais (Lima, 1999, p.73; Maciel, 1998; Bigio, 2000; Diacon, 2006). Os trabalhos para a instalação do fio telegráfico unindo o Rio de Janeiro a outras regiões do Brasil vinham sendo desenvolvidos desde a década de 1880 e em 1906 já haviam alcançado a cidade de Cuiabá.

Junto com o trabalho de construção da linha telegráfica foram realizados diversos estudos científicos sobre a região, com a finalidade de analisar a viabilidade de incorporação do território ao sistema produtivo nacional (Maciel, 1998; Lima, Sá, Sá, 2008). Na opinião de Rondon, tal incorporação seria possível com instalação de redes de comunicação e transporte, povoamento e inserção dos indígenas ao sistema produtivo, respeitando-se sua cultura e seu território (Diacon, 2006, p.28). No início do empreendimento, pouco se sabia sobre os cursos dos rios, as riquezas naturais, as populações que viviam no norte de Mato Grosso e também sobre os aspectos epidemiológicos locais. Membros da Comissão Rondon produziram estudos em botânica, antropologia, geologia, medicina e outras áreas. Além de inventariar o território percorrido, esses estudos prescreviam medidas que poderiam ser adotadas em médio e longo prazos pelo Estado, para tornar efetivo o desenvolvimento local. ${ }^{1}$ Com isso, a Comissão Rondon é considerada inserida nas 'missões civilizatórias' da Primeira República, as quais visavam à incorporação dos sertões, juntamente com outros empreendimentos do início do século XX. Entre essas 'missões', podem ser citadas as viagens científicas do Instituto Oswaldo Cruz (1908-1922), a Comissão Geológica e Geográfica de São Paulo (1886-1931) e a Expedição Cruls ao Planalto Central, em 1892. (Albuquerque et al., 1991; Lima, 1999, p.65; Lima, Hochman, 1996; Lima, Santos, Coimbra Jr., 2005; Maciel, 1998; Diacon, 2006).

Durante os anos de construção da linha telegráfica, o maior problema enfrentado foi com relação às doenças endêmicas na região, em especial a malária. Ainda no início dos trabalhos, concluída a construção do ramal ligando São Luiz de Cáceres à cidade de Mato Grosso (antiga capital da província, outrora denominada Vila Bela da Santíssima Trindade), em fevereiro e março de 1908, um grande surto de malária deixou a salvo apenas 27 pessoas, de um contingente de 228 (Calazans, s.d., p.8). Além disso, foi relativamente alta a rotatividade de médicos na Comissão Rondon até o ingresso de Joaquim Tanajura, em maio de 1909. Três médicos militares atuaram no canteiro de obras da linha telegráfica nos dois primeiros anos, e apenas um trabalhou por mais de nove meses na região. Todos foram remanejados para outras missões por ordem do Ministério da Guerra. Até 1908, o Exército brasileiro contava com pouco mais de 190 oficiais médicos, constantemente deslocados para diferentes regiões do país, conforme as necessidades da instituição (Silva, 1958, 
p.140). Essa rotatividade era um dos motivos a dificultar a organização de um serviço de profilaxia contra a malária visando à saúde de trabalhadores da Comissão.

Em finais de março de 1909, o Ministério da Viação e Obras Públicas requisitou os serviços do doutor Joaquim Augusto Tanajura, primeiro-tenente médico da Força Policial do Distrito Federal, para chefiar o serviço de saúde da Comissão. Diferentemente dos anteriores, tratava-se de policial militar do Distrito Federal e não de oficial do Exército, portanto mobilizado por outro ministério que não o da Guerra.

As obras iniciadas em 1907 estavam então relativamente avançadas. Já havia sido inaugurada a linha Cáceres-Mato Grosso, além de várias estações da chamada linha tronco, que efetivamente ligaria Santo Antônio do Madeira a Cuiabá e ao Rio de Janeiro. A parte mais temida daquela missão, entretanto, ainda estava por vir, já que os trabalhadores adentrariam a região situada entre as proximidades do rio Juruena e o povoado de Santo Antônio do Madeira, área pouco conhecida, com povos indígenas não pacificados e limítrofe com os aglomerados populacionais do Alto Madeira. Estes eram bem conhecidos e, graças às repetidas tentativas frustradas de construção da ferrovia Madeira-Mamoré, possuíam má fama por apresentar altos índices endêmicos de malária (Hardman, 1988).

Joaquim Tanajura, filho do médico e político José de Aquino Tanajura, nasceu em 1878, no interior da Bahia, e em 1900 doutorou-se em medicina pela Faculdade de Medicina da Bahia, com a tese Letalidade infantil e suas causas (Tanajura, 1900). Alguns anos após militar pela assistência à infância e prevenção da mortalidade infantil, por meio da publicação de artigos na imprensa baiana, mudou-se para a capital federal, onde entrou para a Força Policial. Chefiou o serviço de saúde da Comissão de Linhas Telegráficas Estratégicas de Mato Grosso ao Amazonas entre 1909 e 1912, quando foi nomeado pelo então governador de Mato Grosso, Joaquim Augusto da Costa Marques (1911-1915), o primeiro intendente municipal de Santo Antônio do Madeira, cargo que ocupou até o final de 1915 (Cantanhede, 1950, p.59).

Da chegada de Joaquim Tanajura ao Mato Grosso, em maio de 1909, até a retirada emergencial, para o Rio de Janeiro, de quase todos os oficiais da Comissão - entre eles Cândido Rondon - devido a forte surto de malária, o médico baiano atuou praticamente sozinho contra as doenças e outros males que afligiam os soldados e trabalhadores civis.

Além da construção da linha telegráfica, em 1909 ocorreram os serviços de exploração do norte do Mato Grosso, que mapearam a região reconhecendo cursos de rios e estabelecendo o percurso de prosseguimento da construção da linha. Ao chegar próximo aos seringais do Madeira, Joaquim Tanajura teve também que acudir os habitantes locais, que enfrentavam surtos de malária e influenza. Nesse período, o médico realizou estudos sobre as doenças e seus ciclos de duração na região e aspectos de vida dos trabalhadores da

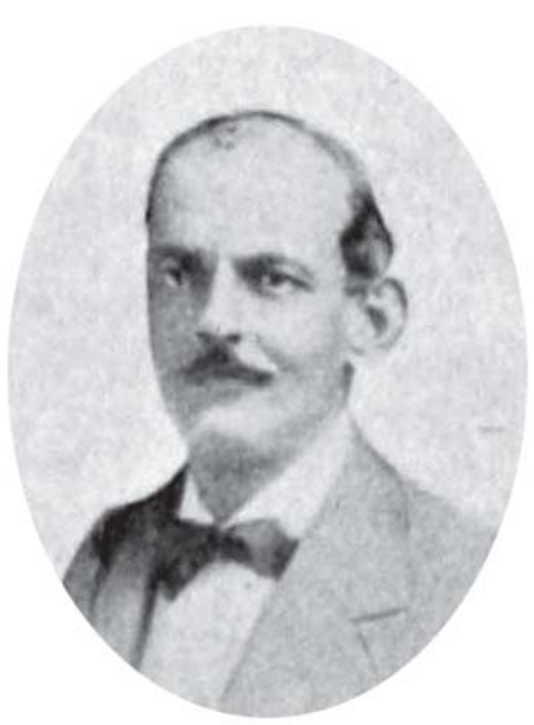

Figura 1: Joaquim Augusto Tanajura em 1909 (Rondon, 1916. p.209) 
Comissão e dos habitantes locais, como, por exemplo, sua alimentação diária. Analisou também alguns rios e córregos utilizados como fonte de água potável. Nessa época, segundo os habitantes do Alto Madeira e o próprio Rondon, a malária se manifestava de modo muito mais intenso, especialmente naquele ano, e gerava grande calamidade sanitária em diversos povoados, entre eles Santo Antônio do Madeira. ${ }^{2}$

Dessas experiências dramáticas com a malária resultou, em 1910, Instruções para o serviço sanitário das seções do norte e do sul (CLTEMTA, s.d.), uma série de normas que visava instituir um serviço de profilaxia contra a malária no contingente de trabalhadores e organizar o serviço de saúde na Comissão. Os trabalhos de construção da linha telegráfica, a partir de maio de 1910, se dariam em duas frentes, dividindo-se, assim, nas seções norte e sul. A primeira teria como centro de tomadas de decisão o povoado de Santo Antônio do Madeira, onde seria instalada também a enfermaria do norte. Entre o final de julho e o começo de agosto de 1910, Joaquim Tanajura, à frente do serviço de saúde, seguiu em expedição liderada pelo major Gomes de Castro com 280 homens do 5을atalhão de Engenharia para Santo Antônio do Madeira, a fim de iniciar os trabalhos da Seção do Norte (Lobato Filho, 1957, p.9).

\section{As crises sanitárias em Santo Antônio do Madeira em 1910}

Apesar da organização de um serviço de saúde para a Comissão e da rigidez com que se buscou colocar em prática as normas sanitárias, não foi possível obter resultados durante todo o ano de 1910. Em agosto daquele ano, a expedição chegou ao povoado de Santo Antônio do Madeira. Em pouco mais de um mês, a Seção do Norte seria dissolvida pela epidemia de malária que atingia o Madeira, e os trabalhos foram paralisados. Do Rio de Janeiro, Rondon nomeava novos chefes para a Seção do Norte, a fim de evitar que os trabalhos permanecessem paralisados, mas esse esforço mostrou-se inútil, já que todos contraíram a doença e se retiraram para Manaus. No final de outubro, o coronel Pantaleão Telles, inspetor da região militar, impediria o desembarque de mais um contingente de soldados enviados por Rondon a Santo Antônio do Madeira, devido à grave crise sanitária no povoado. Era a vitória da malária sobre a Comissão. As atividades só seriam retomadas em 1911.

Os relatos de Carl Lovelace (1912), chefe do serviço de saúde da Madeira-Mamoré, cuja sede ficava no Hospital da Candelária, em Porto Velho, distante sete quilômetros de Santo Antônio, mostram, entretanto, que a malária estava longe de ser a única doença a assolar a região naquele período. Entre 1909 e 1911 houve, em Porto Velho e na região do Madeira, epidemias de febre tifoide, influenza, febre amarela e varíola. As duas últimas seriam determinantes para o fechamento da divisa entre Santo Antônio do Madeira e Porto Velho, no intuito de impedir que essas doenças chegassem até a sede de operações da ferrovia. A malária, portanto, era apenas uma 'transversal' num universo de crises sanitárias que ocorreram em Santo Antônio e nas margens do Madeira.

Além do problema com as doenças, em fevereiro de 1911 o povoado teve que acolher os condenados da Revolta da Chibata e criminosos vindos do Rio de Janeiro. Segundo Hardman (1988, p.156-160), 105 marinheiros, 292 homens e 44 mulheres da casa de detenção 
foram deportados para o Alto Madeira. Parte desse contingente foi destinada às obras da ferrovia Madeira-Mamoré, mas a empresa impediu o desembarque dos que chegaram em estado deplorável, doentes e famintos. A quase totalidade seguiu para trabalhar na Comissão, e as mulheres, em sua maioria, tornaram-se prostitutas em Santo Antônio. Quanto aos homens entregues à Comissão, a maior parte morreu de malária. O impacto da chegada dessas pessoas foi dramático, porque elas se tornaram reservatórios do Plasmodium, favorecendo o ciclo de propagação da malária na região, e também contribuíram para acirrar a miséria do povoado, que antes contava com menos de dois mil habitantes.

\section{A visita de Oswaldo Cruz}

Não só a Comissão Rondon enfrentava problemas graves nesse período em Santo Antônio. A sete quilômetros de distância, em local mais elevado, Porto Velho também sofria as consequências das doenças que se alastravam em meio aos trabalhadores da Estrada de Ferro Madeira-Mamoré. A empresa de Percival Farquhar decidiu, em 1910, contratar os serviços de Oswaldo Cruz, pois além de acreditar que seus conhecimentos poderiam ser úteis para dar continuidade aos serviços de construção da ferrovia, esperava neutralizar as fortes críticas que vinha sofrendo por parte da imprensa nacional e internacional (Benchimol, Silva, 2008 p.743).

Em 9 de julho de 1910, antes do retorno de Joaquim Tanajura ao Alto Madeira, Oswaldo Cruz chegou com Belisário Penna em Porto Velho. Sua missão era analisar a situação na região e preconizar medidas de saúde a serem adotadas para viabilizar a construção da ferrovia. Entretanto, o diretor do Instituto Oswaldo Cruz seria convidado, por membros da própria empresa, a ir a Santo Antônio do Madeira, palco das primeiras iniciativas de construção da Madeira-Mamoré, para estudar a situação do povoado e prescrever o que ali poderia ser feito.

Oswaldo Cruz permaneceu 28 dias em Porto Velho. Em setembro, entregou à MadeiraMamoré Railway Company um relatório com suas impressões e um conjunto de medidas que julgava necessárias, todas circunscritas aos trabalhadores da ferrovia. Nesse relatório, a parte sobre o povoado de Santo Antônio do Madeira tem pouco menos de duas páginas e descreve as condições de vida e salubridade dali. Há críticas aos costumes da população local, a exemplo do tratamento do lixo e dos restos de animais abatidos, que formavam monturos apoiados às paredes das casas, provocando mau cheiro constante nas ruas. Destaca a inexistência de esgoto, água encanada e iluminação de qualquer tipo, e afirma que a malária, "sem exagero", afetava toda a população. Seu relato reforça a imagem também veiculada pela Comissão Rondon e que se tornou célebre: a de uma cidade sem crianças. Oswaldo Cruz aponta esse fato salientando que as poucas que ali nasciam ou chegavam morriam todas (Cruz, Chagas, Peixoto, 1972, p.10-11).

Três linhas de seu relatório expõem o fato de Santo Antônio do Madeira render anualmente, em impostos, quarenta contos de réis à municipalidade amazonense de Humaitá e que nada era feito em benefício do povoado, como contrapartida. Entretanto, é difícil saber se realmente o higienista considerava viável reverter as condições sanitárias locais, até porque nenhuma medida de saúde para o povoado foi prescrita em seu relatório. 


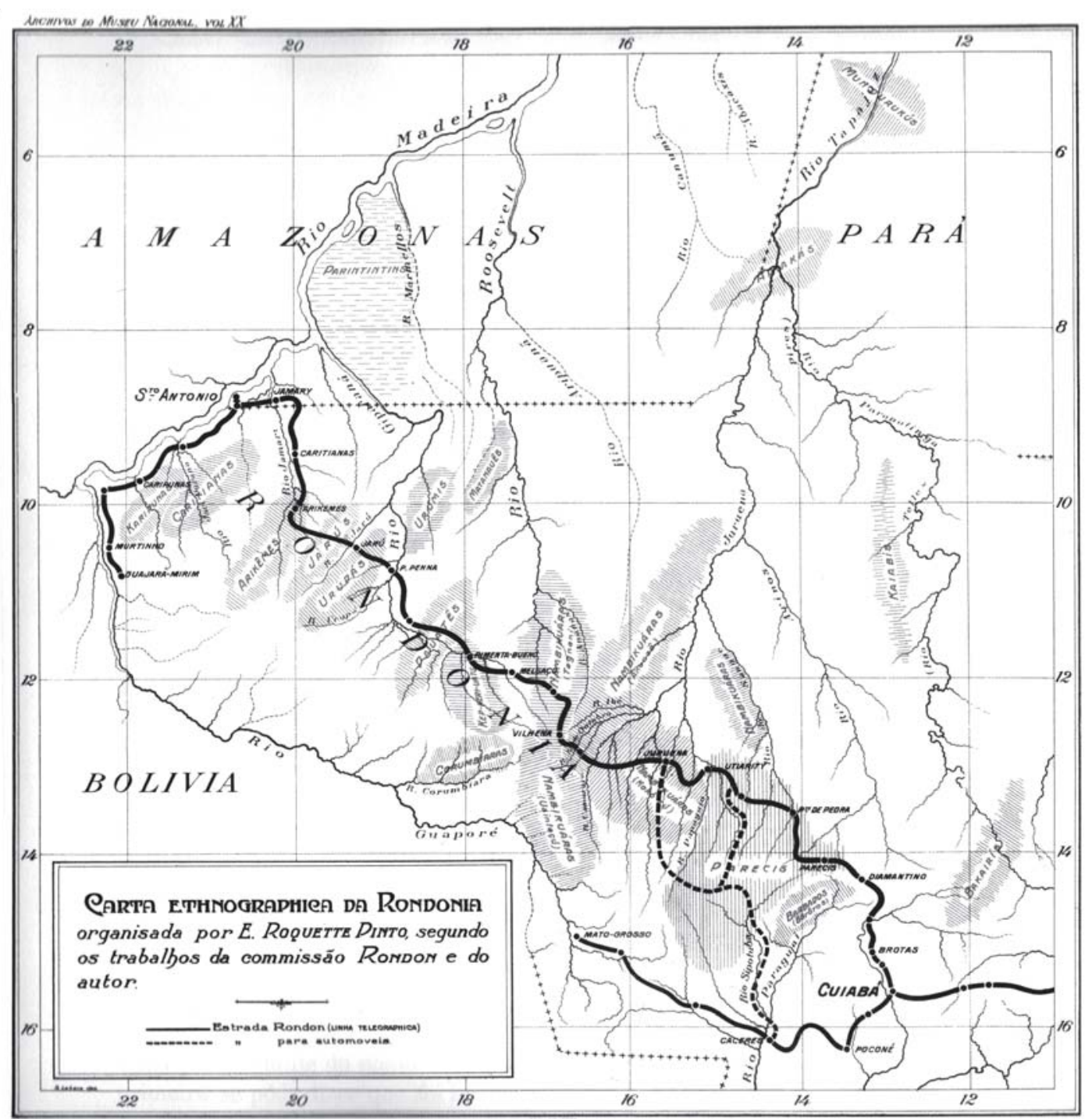

Figura 2: Carta etnográfica de Rondônia conforme os trabalhos da Comissão Rondon (Roquette-Pinto, 2005, p.31)

Lobato Filho, que trabalhou na Comissão Rondon no tempo da primeira tentativa de construção da linha telegráfica na Seção do Norte, comenta, em seu livro de memórias, que Oswaldo Cruz, após breve estudo em Santo Antônio, teria afirmado que "a única solução era incendiar aquilo" (Lobato Filho, 1957, p.22).

\section{Joaquim Tanajura e a defesa de Santo Antônio}

Em maio de 1911, Joaquim Tanajura esteve em Manaus e visitou a redação do Jornal do Commercio de Manáos. Já havia concedido entrevistas a esse e outros jornais do Amazonas em 1910 e era muito respeitado por ter atuado na imprensa baiana. Em junho o periódico manauara publicou, em sua primeira página, "Região do Madeira: Santo Antônio", artigo 
escrito por Tanajura (5 jun. 1911), em que ele relata com riqueza de detalhes a situação do povoado. Mais do que isso, o texto é um conjunto de críticas ao que seriam fatores impeditivos do desenvolvimento da cidade e um apelo às autoridades para que algo fosse feito com urgência. Enquanto no relatório de Oswaldo Cruz salta aos olhos a crítica aos costumes dos habitantes, principalmente a não observância de preceitos de higiene, no artigo de Tanajura não faltam elogios à solidariedade do povoado diante das doenças e da miséria. As críticas do médico baiano são dirigidas àqueles que, embora cientes das mazelas do povoado, nada faziam. Tanajura denunciava problemas políticos da alta administração dos estados, o que explicaria o abandono da localidade, e invocava o artigo $6^{\circ}$ da Constituição de 1891, que previa a intervenção do governo federal para o restabelecimento da ordem.

Em 1910, teve lugar na Assembleia Legislativa do Amazonas a votação da chamada Convenção de Limites entre os estados de Mato Grosso e Amazonas. Trata-se de acordo celebrado provisoriamente entre os dois estados, em 29 de outubro de 1904, determinando que Santo Antônio do Madeira ficaria sob a jurisdição do Amazonas, sendo território pertencente ao município de Humaitá, assim como Porto Velho. O congresso do Amazonas, no entanto, não aprovou a Convenção de 1904 e entrou então em vigor uma antiga determinação de 1899, do Supremo Tribunal, que estabelecia o limite dos dois estados no paralelo situado a $8^{\circ} 48^{\prime}$, o que deixava Santo Antônio sob a jurisdição de Mato Grosso, continuando Porto Velho ligado ao Amazonas.

O acordo entre os dois estados com base na determinação do Supremo Tribunal foi firmado em 14 de setembro de 1910 (Estado de Mato Grosso, 1911, p.50-51). Ressalte-se que isso aconteceu menos de um mês antes do bombardeio a Manaus ordenado por Pinheiro Machado, que depôs o então governador Antônio Clemente Ribeiro Bittencourt, refugiando-se este em Belém (Ferreira, 2007, p.228). O presidente do estado de Mato Grosso era Pedro Celestino Corrêa da Costa, alinhado a Hermes da Fonseca e Pinheiro Machado, sendo este um expoente do Partido Republicano Conservador (PRC) que, na época, fazia, em Manaus, considerável oposição a Bittencourt. É possível que o acordo não tenha sido aprovado devido ao embate político, como forma de enfraquecer o governador do Amazonas.

Embora as críticas de Joaquim Tanajura fossem explosivas, elas estavam em sintonia com o cenário político, uma vez que, em seu manifesto, o médico apoiava a continuidade do PRC no governo de Mato Grosso, por meio da candidatura de Joaquim Augusto da Costa Marques. Este, por sua vez, prometia fazer melhorias no povoado de Santo Antônio. Ademais, Tanajura fazia suas denúncias num jornal do Amazonas, onde o poder ainda estava em mãos de um inimigo político de Hermes. Portanto, o artigo representava a entrada de Joaquim Tanajura no jogo político local.

Após a publicação do artigo e da subsequente vitória de Joaquim Augusto da Costa Marques nas eleições para a Presidência de Mato Grosso, ainda em 1910, houve mudanças no povoado de Santo Antônio. As principais relacionaram-se à vacinação contra varíola e à organização de uma estrutura municipal com juiz, delegacia de polícia e nomeação de um intendente municipal. Para esse cargo foi nomeado Joaquim Augusto Tanajura, que deixou então a Comissão Rondon, filiou-se ao PRC e iniciou carreira na política local. 
$\mathrm{O}$ artigo aqui reproduzido apresenta uma visão alternativa à de Oswaldo Cruz sobre a região do Alto Madeira. Revela o ponto de vista de um médico do interior da Bahia que adentra o interior do Brasil, identifica-se com a região e não mais retorna aos centros urbanos litorâneos. Após um ano de convivência com a população de Santo Antônio, compartilhando seus males em momento de aguda crise sanitária, seus sentimentos, costumes e cotidiano, o médico desenvolveu uma perspectiva mais pragmática, de defesa dos direitos de uma população que, a seu ver, parecia nem pertencer ao Brasil, dado o abandono em que se encontrava. Assim, unindo a formação em medicina, sua experiência na imprensa e o tino político herdado do pai, Joaquim Tanajura se lançou na política em defesa do Alto Madeira.

\section{NOTAS}

${ }^{1}$ São exemplos desses estudos, os de botânica, escritos por Frederico Hoehne e Geraldo Kuhlman; os de zoologia, por Alípio de Miranda Ribeiro; e os trabalhos etnográficos de Edgard Roquette-Pinto.

2 Segundo os médicos da Madeira-Mamoré Railway Company, isso se dava por uma mudança no regime das águas do rio Madeira, que em 1909 alcançou altura muito superior à normal na época da cheia, para logo depois atingir grande baixa no período da vazante, aumentando assim a quantidade de pântanos e águas represadas, e contribuindo para aumentar a população do vetor da doença, o mosquito Anopheles.

\section{REFERÊNCIAS}

ALBURQUERQUE, Marli B. et al.

A ciência a caminho da roça: imagens das expedições científicas do Instituto Oswaldo Cruz ao interior do Brasil entre 1911 e 1913. Rio de Janeiro: Fiocruz/Casa de Oswaldo Cruz, 1991.

BENCHIMOL, Jaime L.; SILVA, André Felipe C. da.

Ferrovias, doenças e medicina tropical no Brasil da Primeira República. História, Ciências, Saúde - Manguinhos, Rio de Janeiro, v.15, n.3, p.719-762. 2008.

BIGIO, Elias dos S.

Cândido Rondon: a integração nacional. Rio de Janeiro: Contraponto. 2000.

CALAZANS, Armando.

Serviço sanitário: secção de Cáceres à Matto Grosso pelo dr. Armando de Calazans, primeiro tenente médico, secção da Linha Tronco por Joaquim Pinto Rabello, primeiro tenente médico. Rio de Janeiro: Papelaria Luiz Macedo. s.d.

CANTANHEDE, Antonio de J.

Achegas para história de Porto Velho. Manaus: Secção de Artes Gráficas da Escola Técnica de Manaus. 1950.

\section{CLTEMTA.}

Comissão de Linhas Telegráficas Estratégicas de Mato Grosso ao Amazonas. Instrucções para o
Serviço Sanitário das Secções Norte e do Sul. In: CLTEMA. Relatórios diversos: projectos, orçamentos, medições, observações meteorológicas, etc. Rio de Janeiro: Papelaria Luiz Macedo. s.d.

CRUZ, Oswaldo; CHAGAS, Carlos; PEIXOTO, Afrânio.

Sobre o saneamento da Amazônia. Manaus:

P. Daou. 1972.

DIACON, Todd A.

Rondon: o marechal das florestas. Trad., Laura Teixeira Motta. São Paulo: Companhia das Letras. 2006.

ESTADO DE MATO GROSSO.

Mensagem do vice-presidente Pedro Celestino Corrêa da Costa de 13 de maio de 1911. Cuiabá: Imprensa Oficial. 1911.

FERREIRA, Sylvio Mario Puga.

Federalismo, economia exportadora e representação política: o Amazonas na República Velha (1889-1914). Manaus: Ed. da Universidade Federal do Amazonas. 2007.

HARDMAN, Francisco F.

Trem fantasma: a modernidade na selva. São Paulo: Companhia das Letras. 1988.

LIMA, Nísia T.

Um sertão chamado Brasil: intelectuais e representação geográfica da identidade nacional. Rio de Janeiro: Revan. 1999. 
LIMA, Nísia T.; SÁ, Dominichi M. de; SÁ, Magali R.

Telégrafos e inventário do território no Brasil: as atividades científicas da Comissão Rondon (1907-1915). História, Ciências, Saúde Manguinhos, Rio de Janeiro, v.15, n.3, p.779-810. 2008.

LIMA, Nísia T.; HOCHMAN, Gilberto. Condenado pela raça, absolvido pela medicina: o Brasil descoberto pelo movimento sanitarista da Primeira República. In: Maio, Marcos C; Santos, Ricardo V. (Org.). Raça, ciência e sociedade. Rio de Janeiro: Ed. Fiocruz; CCBB. p.23-40. 1996.

LIMA, Nísia T.; SANTOS, Ricardo V.; COIMBRA JR., Carlos E.A.

Introdução à Rondônia de Edgard RoquettePinto. In: Roquette-Pinto, E. Rondonia: anthropologia - ethnographia. 7.ed. Rio de Janeiro: Ed. Fiocruz. p.25-39. 2005.

LOBATO FILHO, João Bernardo. Avançai para o Jamari!: a Comissão Rondon nas selvas do Alto Madeira. Rio de Janeiro: s.n. 1957.

LOVELACE, Carl.

Os trabalhos da secção médica da Madeira-
Mamoré Railway. Medicina Militar, Rio de Janeiro, ano 2, n.11, p.505-511. 1912.

MACIEL, Laura Antunes.

A nação por um fio: caminhos, práticas e imagens da Comissão Rondon. São Paulo: Educ. 1998.

RONDON, Cândido Mariano da Silva. Conferências de 1915: referentes a trabalhos executados na expedição científica RooseveltRondon e pela Comissão Telegráfica. Rio de Janeiro: Tipografia do Jornal do Commercio. 1916.

ROQUETTE-PINTO, Edgard.

Rondonia: anthropologia - ethnographia. 7.ed. Rio de Janeiro: Editora Fiocruz. 2005.

SILVA, Arthur Lobo da.

O Serviço de Saúde do Exército Brasileiro.

Rio de Janeiro: Biblioteca do Exército. 1958.

TANAJURA, Joaquim Augusto.

Região da Madeira: Santo Antonio, Jornal do Commercio de Manáos, Manaus. 5 jun. 1911.

TANAJURA, Joaquim Augusto.

Letalidade infantil e suas causas. Tese (doutoramento), Faculdade de Medicina da Bahia, Salvador. 1900. 


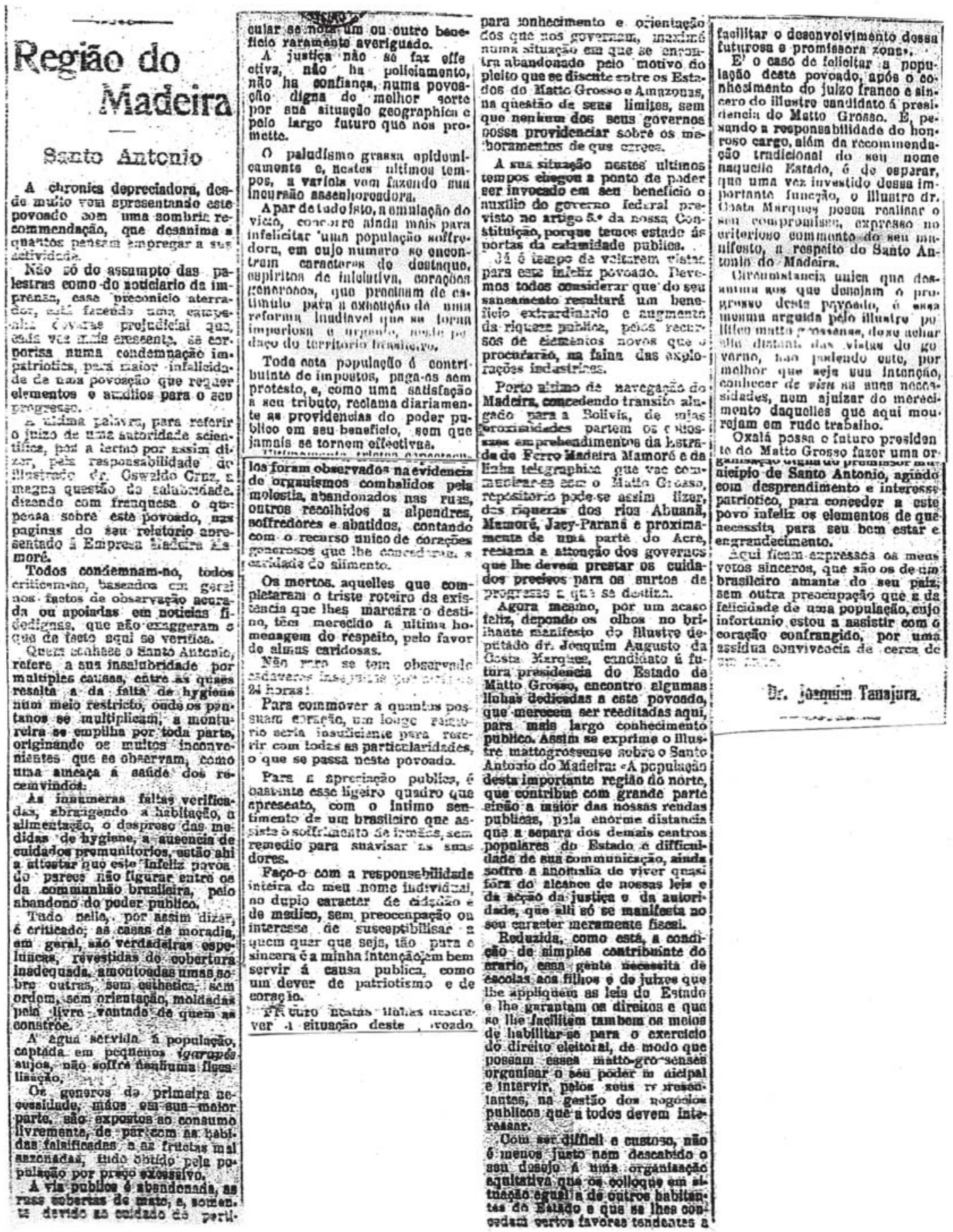

Figura 3: Fac-símile do artigo de Joaquim Tanajura, "Região do Madeira Santo Antonio" 


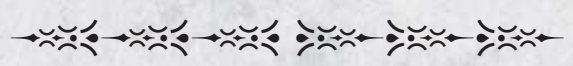

\title{
Região do Madeira
}

\author{
Santo Antônio
}

A crônica depreciadora, desde muito vem apresentando este povoado com uma sombria recomendação, que desanima a quantos pensam empregar a sua atividade.

Não só do assunto das palestras como do noticiário da imprensa, esse preconício aterrador está fazendo uma campanha deveras prejudicial que, cada vez mais crescente, se corporiza numa condenação impatriótica, para maior infelicidade de uma povoação que requer elementos e auxílios para seu progresso.

A última palavra para referir o juízo de uma autoridade científica pôs o termo, por assim dizer, pela responsabilidade do ilustrado dr. Oswaldo Cruz, a magna questão de salubridade, dizendo com franqueza o que pensa sobre este povoado, nas páginas de seu relatório apresentado à Empresa Madeira Mamoré.

Todos condenam-no, todos criticam-no, baseados em geral nos fatos de observação acurada ou apoiados em notícias fidedignas, que não exageram o que de fato aqui se verifica.

Quem conhece o Santo Antônio refere a sua insalubridade por múltiplas causas, entre as quais ressalta a da falta de higiene num meio restrito, onde os pântanos se multiplicam, a montureira se empilha por toda parte, originando os muitos inconvenientes que se observam como uma ameaça à saúde dos recém-vindos.

As inúmeras faltas verificadas, abrangendo a habitação, a alimentação, o desprezo das medidas de higiene, a ausência de cuidados premunitórios estão aí a atestar que este infeliz povoado parece não figurar entre os da comunhão brasileira, pelo abandono do poder público.

Tudo nele, por assim dizer, é criticado; as casas de moradia, em geral, são verdadeiras espeluncas, revestidas de cobertura inadequada, amontoadas umas sobre outras, sem estética, sem ordem, sem orientação, moldadas pela livre vontade de quem as constrói.

A água servida à população, captadas em pequenos igarapés sujos, não sofre nenhuma fiscalização.

Os gêneros de primeira necessidade, maus em sua maior parte, são expostos ao consumo livremente, de par com as bebidas falsificadas e as frutas mal sazonadas, tudo obtido pela população por preço excessivo.

A via pública é abandonada, as ruas cobertas de mato, e somente devido ao cuidado do particular se nota um ou outro benefício raramente averiguado.

A justiça não se faz efetiva, não há policiamento, não há confiança, numa povoação digna de melhor sorte por sua situação geográfica e pelo largo futuro que nos promete.

Publicado no Jornal do Commercio de Manáos, Manaus, em 5 de junho de 1911. 
O paludismo grassa epidemicamente e, nestes últimos tempos, a varíola vem fazendo sua incursão assenhoreadora.

A par de tudo isto, a emulação do vício concorre ainda mais para infelicitar uma população sofredora, em cujo número se encontram caracteres de destaque, espíritos de iniciativa, corações generosos, que precisam de estímulo para a execução de uma reforma inadiável que se torna imperiosa e urgente, neste pedaço do território brasileiro.

Toda esta população é contribuinte de impostos, paga-os sem protesto e, como uma satisfação a seus tributos, reclama diariamente as providências do poder público em seu benefício, sem que jamais se tornem efetivas.

Ultimamente, tristes espetáculos foram observados na evidência de organismos combalidos pela moléstia, abandonados nas ruas, outros recolhidos a alpendres, sofredores e abatidos, contando com o recurso único de corações generosos que lhe concederam a caridade do alimento.

Os mortos, aqueles que completaram o triste roteiro da existência que lhes marcara o destino, têm merecido a última homenagem do respeito, pelo favor de almas caridosas.

Não raro se tem observado cadáveres insepultos por mais de 24 horas!

Para comover a quantos possuem coração, um longo relatório seria insuficiente para referir com todas as particularidades o que se passa neste povoado.

Para a apreciação pública, é bastante esse ligeiro quadro que apresento, com o íntimo sentimento de um brasileiro que assiste o sofrimento de irmãos sem remédio para suavizar as suas dores.

Faço-o com a responsabilidade inteira do meu nome individual, no duplo caráter de cidadão e de médico, sem preocupação ou interesse de suscetibilizar a quem quer que seja, tão pura e sincera é a minha intenção em bem servir à causa pública como um dever de patriotismo e de coração.

Procuro nestas linhas descrever a situação deste povoado para conhecimento e orientação dos que nos governam, máxime numa situação em que se encontra abandonado pelo motivo do pleito que se discute entre os Estados do Mato Grosso e Amazonas, na questão de seus limites, sem que nenhum dos seus governos possa providenciar sobre os melhoramentos de que carece.

A sua situação nestes últimos tempos chegou a ponto de poder ser invocado em seu benefício o auxílio do governo federal previsto no artigo $6^{\circ}$ da nossa Constituição, porque temos estado às portas da calamidade pública.

Já é tempo de voltarem vistas para este infeliz povoado. Devemos todos considerar que do seu saneamento resultará um benefício extraordinário e aumento da riqueza pública, pelos recursos de elementos novos que o procurarão, na faina das explorações industriais.

Porto último de navegação do Madeira, concedendo trânsito alugado para a Bolívia, de cujas proximidades partem os colossais empreendimentos da Estrada de Ferro Madeira Mamoré e da linha telegráfica que vai comunicar-se com o Mato Grosso, repositório, pode-se assim dizer, das riquezas dos rios Abuanã, Mamoré, Jacy-Paraná e proximamente de uma parte do Acre, reclama a atenção dos governos que lhe devem prestar os cuidados precisos para os surtos de progresso a que se destina. 
Agora mesmo, por um acaso feliz, depondo os olhos no brilhante manifesto do ilustre deputado dr. Joaquim Augusto da Costa Marques, candidato à futura presidência do Estado de Mato Grosso, encontro algumas linhas dedicadas a este povoado, que merecem ser reeditadas aqui, para mais largo conhecimento público. Assim se exprime o ilustre matogrossense sobre o Santo Antônio do Madeira:

A população desta importante região do norte, que contribui com grande parte, senão a maior, das nossas rendas públicas, pela enorme distância que a separa dos demais centros populares do Estado e dificuldade de sua comunicação, ainda sofre a anomalia de viver quase fora do alcance de nossas leis e da ação da justiça e da autoridade, que ali só se manifesta no seu caráter meramente fiscal.

Reduzida, como está, à condição de simples contribuinte do erário, essa gente necessita de escolas aos filhos e de juízes que lhe apliquem as leis do Estado e lhe garantam os direitos e que se lhe facilitem também os meios de habilitar-se para o exercício do direito eleitoral, de modo que possam esses mato-grossenses organizar o seu poder municipal e intervir pelos seus representantes, na gestão dos negócios públicos que a todos devem interessar.

Com ser difícil e custoso, não é menos justo nem descabido o seu desejo a uma organização equitativa que os coloque em situação igual a de outros habitantes do Estado e que se lhes concedam certos favores tendentes a facilitar o desenvolvimento dessa futurosa e promissora zona.

É o caso de felicitar a população deste povoado, após o conhecimento do juízo franco e sincero do ilustre candidato à presidência do Mato Grosso. E, pensando a responsabilidade do honroso cargo, além da recomendação tradicional do seu nome naquele Estado, é de esperar que, uma vez investido dessa importante função, o ilustre dr. Costa Marques possa realizar o seu compromisso, expresso no criterioso comento do seu manifesto, a respeito do Santo Antônio do Madeira.

Circunstância única, que desanima aos que desejam o progresso deste povoado, é essa mesma arguida pelo ilustre político mato-grossense, de se achar ele distante das vistas do governo, não podendo este, por melhor que seja sua intenção, conhecer de visu as suas necessidades, nem ajuizar do merecimento daqueles que aqui mourejam em rude trabalho.

Oxalá possa o futuro presidente do Mato Grosso fazer uma organização digna do promissor município de Santo Antônio, agindo com desprendimento e interesse patriótico, para conceder a este povo infeliz os elementos de que necessita para seu bem-estar e engrandecimento.

Aqui ficam expressos os meus votos sinceros que são os de um brasileiro amante do seu país, sem outra preocupação que a da felicidade de uma população cujo infortúnio estou a assistir com o coração confrangido, por uma assídua convivência de cerca de um ano.

Dr. Joaquim Tanajura 